\title{
Isoflurane suppresses the self-renewal of normal mouse neural stem cells in a p53-dependent manner by activating the Lkb1-p53-p21 signalling pathway
}

\author{
LENGCHEN HOU $^{1}$, TE LIU ${ }^{1,2}$ and JIAN WANG ${ }^{3}$ \\ ${ }^{1}$ Department of Anesthesiology, Shanghai Tenth People's Hospital, Medical School, Tongji University, Shanghai 200072; \\ ${ }^{2}$ Shanghai Geriatric Institute of Chinese Medicine, Longhua Hospital, Shanghai University of Traditional Chinese Medicine; \\ ${ }^{3}$ School of Rehabilitation Science, Shanghai University of Traditional Chinese Medicine, Shanghai 200031, P.R. China
}

Received February 17, 2015; Accepted September 11, 2015

DOI: $10.3892 / \mathrm{mmr} .2015 .4387$

\begin{abstract}
Isoflurane is widely used in anaesthesia for surgical operations. However, whether it elicits unwanted side effects, particularly in neuronal cells, remains to be fully elucidated. The Lkb1-p53-p21 signalling pathway is able to modulate neuronal self-renewal and proliferation. Furthermore, the suppression of Lkb1-dependent p21 induction leads to apoptosis. In the present study, whether Lkb1-p53-p21 signalling is involved in the response to isoflurane was investigated. A comparison of mouse primary, wild-type neural stem cells (WT NSCs) with the p53 ${ }^{-/}$NSC cell line, NE-4C, revealed that isoflurane inhibited proliferation in a dose-, a time- and a p53-dependent manner. However, flow cytometric analysis revealed that the concentration of isoflurane which caused $50 \%$ inhibition (the $\mathrm{IC}_{50}$ value) induced cell cycle arrest in WT NSCs. Furthermore, the protein expression levels of LKB1, p53 and p21 were increased, although those of nestin and survivin decreased, following treatment of WT NSCs with isoflurane. On the other hand, isoflurane induced the phosphorylation of Ser15 in p53 in WT NSCs, which was associated with p53 binding to the p21 promoter, and consequentially, the transcriptional activation of p21. All these events were abrogated in NE-4C cells. Taken together, the present study has demonstrated that isoflurane suppresses the self-renewal of normal mouse NSCs by activating the Lkb1-p53-p21 signalling pathway.
\end{abstract}

Correspondence to: Professor Te Liu, Shanghai Geriatric Institute of Chinese Medicine, Longhua Hospital, Shanghai University of Traditional Chinese Medicine, No. 558 Xiangyang South Road, Shanghai 200031, P.R. China

E-mail: teliu79@126.com

Professor Jian Wang, School of Rehabilitation Science, Shanghai University of Traditional Chinese Medicine, No. 1200 Cailun Road, Shanghai 200031, P.R. China

E-mail: wangjiantcm@126.com

Key words: isoflurane, self-renewal, Lkb1-p53-p21 signalling pathway, neural stem cells

\section{Introduction}

Isoflurane is widely used in the clinic as a volatile anaesthetic. Previous studies revealed that preconditioning with isoflurane mimics the protective effects of early and delayed ischemic preconditioning in the brain (1-6). Isoflurane produced early preconditioning against spinal cord ischemic injury (6). However, whether isoflurane produces delayed preconditioning in neural stem cells (NSCs) remains to be fully elucidated. The serine/threonine kinase, LKB1 (also known as STK11), has assumed a prominent position among tumour suppressors (7-9). LKB1 is inactivated in individuals with Peutz-Jeghers syndrome, which is a familial cancer-prone disease (10). Best characterized as an upstream activator of the adenine monophosphate-activated protein kinase and the mammalian target of rapamycin pathways (10), LKB1 regulates cellular and organismal metabolism, cell polarity and a variety of other functions, ranging from proliferation and migration to senescence, apoptosis, the DNA damage response and differentiation $(7,11)$. Zeng et al (12) reported that LKB1 physically associates with p53 in the nucleus and phosphorylates p53 at the amino acid residues Ser15 and Ser392. LKB1 is also recruited directly to the p21/WAF1 promoter and other p53-activated promoters, and thereby regulates the cell cycle. Furthermore, Liang et al (13) identified that knockdown of the endogenous LKB1 facilitated cell cycle progression through the G1 and S phases, which was, at least in part, due to a reduced activity of the p53 and p16 pathways (13). In addition, Liu et al (8) reported that the inactivation of LKB1 in the presence of active Ras facilitated metastasis, which was proposed to be mediated via the Src family kinase-dependent expansion of a CD24+ melanoma prometastatic tumour subpopulation (8). On the basis of these studies, the present study aimed to investigate whether the Lkb1-p53-p21/WAF1 axis has a regulatory role in the modulation of normal mouse NSC proliferation during isoflurane treatment.

\section{Materials and methods}

Isolation of the mouse NSCs. Mouse NSCs were isolated from the corpus striatum of the embryonic brain in a 13-day-old 
pregnant mouse. Isolation of the NSCs was performed as previously described (14). Briefly, the embryonic brain tissue was sectioned into small segments with a razor. The segments were digested with $0.125 \%$ trypsin-EDTA (Sigma-Aldrich, St. Louis, MO, USA) at $37^{\circ} \mathrm{C}$ for $15 \mathrm{~min}$. The resulting cell suspension was seeded in a six-well plate (Falcon, BD Biosciences, Franklin Lakes, NJ, USA) in Dulbecco's modified Eagle's medium (DMEM)/F12 (1:1) (Gibco, Thermo Fisher Scientific, Waltham, MA, USA), supplemented with $1 \%$ (v/v) B27 $7^{\circledR}$ Supplement, $20 \mathrm{ng} / \mathrm{ml}$ epidermal growth factor, $20 \mathrm{ng} / \mathrm{ml}$ basic fibroblast growth factor, $5 \mu \mathrm{g} / \mathrm{ml}$ heparin, $1 \mu \mathrm{g} / \mathrm{ml}$ laminin, $100 \mathrm{U} / \mathrm{ml}$ penicillin and $0.3 \mathrm{mg} / \mathrm{ml}$ glutamine (all from Gibco), and incubated in a humidified tissue culture incubator containing $5 \% \mathrm{CO}_{2}$ at $37^{\circ} \mathrm{C}$. The mouse NSC (p53 ${ }^{--}$) cell line, NE-4C, was kindly provided by the Stem Cell Bank, Chinese Academy of Sciences (Shanghai, China). The NE-4C cells were cultured in DMEM:F12 (1:1) medium, supplemented with $15 \%$ FBS, $1 \mathrm{mM}$ sodium pyruvate, $2 \mathrm{mM}$ L-glutamine, $0.1 \mathrm{mM}$ non-essential amino acids and penicillin $(25 \mathrm{U} / \mathrm{ml})$-streptomycin $(925 \mathrm{mg} / \mathrm{ml})$ (all from Gibco), prior to mixing. The cells were subsequently incubated in a humidified tissue culture incubator containing $5 \% \mathrm{CO}_{2}$ at $37^{\circ} \mathrm{C}$. The cells were cultured on an identical feeder until passage 2, prior to the subsequent experiments.

$R N A$ extraction and analysis by reverse transcription-quantitative polymerase chain reaction ( $R T-q P C R)$. The total RNA from each cell was isolated using TRIzol ${ }^{\circledR}$ reagent (Invitrogen Life Technologies, Carlsbad, CA, USA), according to the manufacturer's instructions. The RNA samples were treated with DNase I (Sigma-Aldrich), quantified, and reverse-transcribed into cDNA using the ReverTra Ace- $\alpha$ First Strand cDNA Synthesis kit (Toyobo Co., Ltd., Osaka, Japan). RT-qPCR was performed using a RealPlex4 real-time PCR detection system from Eppendorf Co., Ltd. (Hamburg, Germany), with SYBR-Green RealTime PCR Master mix (Toyobo Co., Ltd.) used as the detection dye. RT-qPCR amplification was performed over 40 cycles, with denaturation at $95^{\circ} \mathrm{C}$ for $15 \mathrm{sec}$ and annealing at $58^{\circ} \mathrm{C}$ for $45 \mathrm{sec}$. The target cDNA was quantified using the relative quantification method. A comparative threshold cycle $(\mathrm{Ct})$ was used to determine gene expression relative to a control (calibrator), and the steady-state mRNA levels were reported as an n-fold difference relative to the calibrator. For each sample, the $\mathrm{Ct}$ values of the marker genes were normalized using the equation: $\Delta \mathrm{Ct}=\mathrm{Ct}$ _genes $-\mathrm{Ct}$ _18S RNA. The relative expression levels were determined using the equation: $\Delta \Delta \mathrm{Ct}=\Delta \mathrm{Ct}$ _sample_groups $-\Delta \mathrm{Ct}$ _control_group. The values used to plot the relative expression of markers were calculated using the expression $2^{-\Delta \Delta \mathrm{Ct}}$. The mRNA levels were calibrated, based on the levels of $18 \mathrm{~S}$ rRNA. The cDNA of each gene was amplified using the primers listed in Table I.

Immunofluorescence staining. The cultured cells were washed three times with phosphate-buffered saline (PBS) and fixed with $4 \%$ paraformaldehyde (Sigma-Aldrich) for $30 \mathrm{~min}$. For blocking of non-specific binding sites, the samples were incubated with phosphate-buffered saline (Sigma-Aldrich) containing $0.5 \%$ Triton X-100 (Sigma-Aldrich) and 5\% calf serum (Gibco) for $40 \mathrm{~min}$ at $37^{\circ} \mathrm{C}$. Subsequently, the cells were first incubated with a primary antibody (Table II) overnight at $4^{\circ} \mathrm{C}$ and then with fluorescein isothiocyanate-conjugated goat anti-rabbit IgG antibody (1:200; Abcam, Cambridge, UK) and $5 \mu \mathrm{g} / \mathrm{ml} \mathrm{4',6-diamidino-2-phenylindole} \mathrm{(Sigma-Aldrich)}$ at $26^{\circ} \mathrm{C}$ for $30 \mathrm{~min}$. Subsequently, the cells were thoroughly washed with TBS-T buffer and viewed under a fluorescence microscope (DMI3000; Leica, Allendale, NJ, USA).

Co-immunoprecipitation assay. For each experiment, the cells were seeded at $3 \times 10^{5}$ cells/well in six-well plates, cultured until $85 \%$ confluence was reached, and subsequently lysed (500 $\mu \mathrm{l}$ per plate) in a modified cell lysis buffer [20 mM Tris/ $\mathrm{HCl}$, (pH 7.5), $150 \mathrm{mM} \mathrm{NaCl}, 1 \%$ Triton X-100, 1 mM EDTA, sodium pyrophosphate, $\beta$-glycerophosphate, $\mathrm{Na}_{3} \mathrm{VO}_{4}$ and leupeptin; Beyotime Institute of Biotechnology, Shanghai, China), prior to western blot analysis and immunoprecipitation assay. Following lysis, each sample was collected to clear the lysate of the insoluble debris by centrifugation (Allegra 64R; Beckman Coulter, Miami, FL, USA) at 10,000 x g for $10 \mathrm{~min}$, prior to an incubation with $20 \mu \mathrm{g}$ protein A-agarose beads (Beyotime Institute of Biotechnology) by agitation for $30 \mathrm{~min}$ at $4^{\circ} \mathrm{C}$. Subsequently, the samples were centrifuged again at $10,000 \mathrm{x} \mathrm{g}$ for $1 \mathrm{~min}$ and transferred to a fresh $1.5 \mathrm{ml}$ tube. The antibodies (Table II) were incubated with the samples for 90 min prior to the re-addition of $20 \mu \mathrm{g}$ protein A-agarose beads to capture the immune complexes. The pelleted beads were subsequently washed three times with $500 \mu \mathrm{l}$ cell lysis buffer, dissolved in 4X SDS-PAGE sample loading buffer, and heated for $10 \mathrm{~min}$ at $95^{\circ} \mathrm{C}$.

Chromatin immunoprecipitation (ChIP) assays. ChIP experiments were performed using the primary antibodies provided in Table II and normal rabbit immunoglobulin $\mathrm{G}$ (IgG; Upstate Biotechnology, Inc., Lake Placid, NY, USA) as a negative control. All the steps were performed as previously described $(9,12)$. Briefly, the cells were fixed with $1 \%$ formaldehyde for $30 \mathrm{~min}$ at $37^{\circ} \mathrm{C}$, and the reaction was subsequently quenched by the addition of $125 \mathrm{mM}$ glycine for $10 \mathrm{~min}$ at room temperature to form DNA-protein cross-links. The products were sheared by sonication using 4-5 sets of 10 -sec pulses on wet ice with a Cole-Parmer High Intensity Ultrasonic Sonicator (50-watt model; Cole-Parmer Instrument Co., San Diego, CA, USA), equipped with a 2-mm tip and set to $30 \%$ of the maximum power, which produced the appropriate 200-800 bp DNA fragments. Subsequently, the samples were incubated with antibodies at $4^{\circ} \mathrm{C}$ overnight. The PCR amplification experiment was performed under the following conditions: 33 cycles run by denaturation at $95^{\circ} \mathrm{C}$ for $30 \mathrm{sec}$, annealing at $55^{\circ} \mathrm{C}$ for $30 \mathrm{sec}$, and extension at $72^{\circ} \mathrm{C}$ for $30 \mathrm{sec}$. Changes in the binding were expressed as the relative fold enrichment, following the subtraction of the matched $\mathrm{IgG}$ negative control.

Western blot analysis. The total protein extracts from each treatment group were resolved by $12 \%$ SDS-PAGE at $20^{\circ} \mathrm{C}$ over $120 \mathrm{~min}$ and transferred onto polyvinylidene fluoride (PVDF) membranes (Millipore, Billerica, MA, USA). Following blocking, the PVDF membranes were washed four times for 15 min with TBS-T buffer at room temperature, and subsequently incubated with the primary antibodies listed in Table II. Following extensive washing, the membranes were 
Table I. Reverse-transcription quantitative polymerase chain reaction primers used in the present study.

\begin{tabular}{lll}
\hline Gene product & Forward and reverse primers $\left(5^{\prime} \rightarrow 3^{\prime}\right)$ & Size $(\mathrm{bp})$ \\
\hline$L k b 1$ & F: GGGCAACCTGCTACTCACC & 103 \\
& R: CCAGATGTCCACCTTGAAAC & 98 \\
$p 53$ & F: ATGAACCGCCGACCTATC & \\
& R: AGGGCAGGCACAAACACG & F: GCCTTGTCGCTGTCTTGC \\
$18 S$ R RNA & R: GCTGGTCTGCCTCCGTTTT & 241 \\
& F: AGGGGAGAGCGGGTAAGAGA & R: GGACAGGACTAGGCGGAACA \\
\hline
\end{tabular}

F, forward; R, reverse.

Table II. List of primary antibodies used in the present study.

\begin{tabular}{lccc}
\hline Antibody & Cat. no. & Company & Application \\
\hline Rabbit anti-mouse LKB1 & $($ sc-5638) & Santa Cruz Biotechnology, Inc. (Dallas, TX, USA) & WB (1:1,000) \\
& & & IHC (1:200) \\
Rabbit anti-mouse p53, Ser15-pho & $($ sc-101762) & Santa Cruz Biotechnology, Inc. & IHC (1:200) \\
Rabbit anti-mouse p21 & $(2947 S)$ & Cell Signaling Technology, Inc. (Danvers, MA, USA) & WB (1:1,000) \\
& & & IHC (1:200) \\
Rabbit anti-GAPDH & $(5174 S)$ & Cell Signaling Technology & WB (1:1,000)
\end{tabular}

WB, western blotting; IHC, immunohistochemistry; GADPH, glyceraldehyde-3-phosphate dehydrogenase; pho, phosphorylated.

incubated with secondary peroxidase-linked goat anti-rabbit IgG (1:1,000; Santa Cruz Biotechnology, Inc., Santa Cruz, CA, USA) for $1 \mathrm{~h}$. Following a further four washing steps (15 min each) with TBS-T buffer at room temperature, the immunoreactivity was visualized by enhanced chemiluminescence (ECL) using the ECL kit of Pierce Biotechnology, Inc. (Rockford, IL, USA). The membranes were subsequently exposed to Kodak XAR-5 films (Sigma-Aldrich). GAPDH was used as a loading control.

Flow cytometric (FCM) analysis of the cell cycle by propidium iodide (PI) staining. Each group of cells was seeded at $3 \times 10^{5}$ cells/well in six-well plates and cultured until $85 \%$ confluence was reached. The cells were washed three times with PBS, prior to collection by centrifugation (Allegra X-22R, Beckman Coulter, Miami, FL, USA) at $1,000 \times \mathrm{g}$ for $5 \mathrm{~min}$. The cell pellets were subsequently resuspended in $1 \mathrm{ml} \mathrm{PBS}$, fixed in $70 \%$ ice-cold ethanol and kept in a freezer for $>48 \mathrm{~h}$. Prior to flow cytometric analysis, the fixed cells were centrifuged at $1,000 \mathrm{x} \mathrm{g}$ for $5 \mathrm{~min}$, washed twice with PBS, and resuspended in PI staining solution (Sigma-Aldrich), containing $50 \mu \mathrm{l} / \mathrm{ml} \mathrm{PI}$ and $250 \mu \mathrm{g} / \mathrm{ml}$ RNase A (Sigma-Aldrich). The cell suspension, which was protected from the light, was incubated for $30 \mathrm{~min}$ at $4^{\circ} \mathrm{C}$ and analysed by fluorescence-activated cell sorting (FACS) using a BD FACSAria cell sorter (BD Biosciences, Frankin Lakes, NJ, USA). A total of 20,000 events were acquired for analysis using CellQuest software version 2.0 (BD Biosciences).
Methyl thiazolyl tetrazolium (MTT) assay for cell proliferation. Each group of cells was seeded at $2 \times 10^{3}$ cells/well in six-well plates, and cultured in DMEM supplemented with $10 \% \mathrm{FBS}$ at $37^{\circ} \mathrm{C}$ with $5 \% \mathrm{CO}_{2}$ until $85 \%$ confluence was reached. The MTT reagent $(5 \mathrm{mg} / \mathrm{ml}$; Sigma-Aldrich) was added to the maintenance cell medium containing different concentrations of isoflurane $(0,0.125,0.25$ and $0.5 \mathrm{mM})$ for different time periods $(0,12,24$ and $48 \mathrm{~h})$, and incubated at $37^{\circ} \mathrm{C}$ for an additional $4 \mathrm{~h}$. The reaction was terminated by the addition of $150 \mu \mathrm{l}$ dimethylsulfoxide (DMSO; Sigma-Aldrich) per well, and the cells were lysed for $15 \mathrm{~min}$. The plates were subsequently gently agitated for $5 \mathrm{~min}$. The absorbance was measured at $490 \mathrm{~nm}$ using an enzyme-linked immunosorbent assay reader (Model 680; Bio-Rad Laboratories, Hercules, CA, USA).

Statistical analysis. The data in each experiment are shown as the mean \pm standard error of the mean where applicable; differences were evaluated using the Student's t-test. GraphPad Prism version 5.00 (GraphPad Software Inc, La Jolla, CA, USA) was used for statistical analysis. $\mathrm{P}<0.05$ was considered to indicate a statistically significant difference.

\section{Results}

Isoflurane suppresses proliferation of WT NSCs by inducing cell cycle arrest. The results of the MTT assay indicated that isoflurane significantly inhibited the proliferation of 

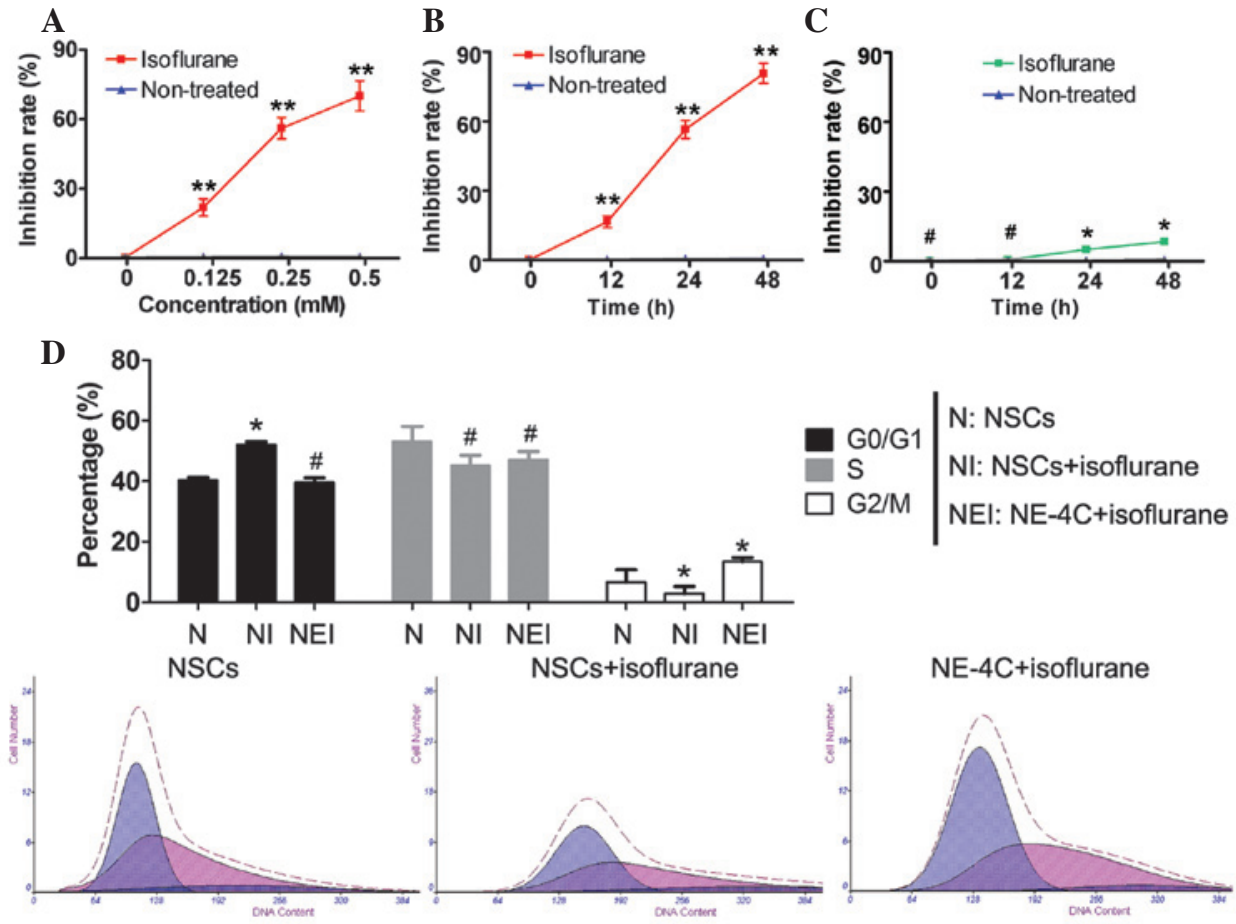

Fig. 1. Isoflurane suppresses proliferation in a p53-dependent manner. (A) The results of the methyl thiazolyl tetrazolium assay indicated that isoflurane inhibited the proliferation of WT NSCs in a dose-dependent manner $\left({ }^{* *} \mathrm{P}<0.01\right.$ compared with the non-treated group; $\left.\mathrm{n}=3\right)$. (B) A significant inhibition of proliferation was observed at all the time points ( ${ }^{* *} \mathrm{P}<0.01$ compared with the non-treated group; $\left.n=3\right)$. (C) Isoflurane fails to induce any significant cell cycle arrest in the absence of $553^{-1-} \mathrm{NE}-4 \mathrm{C}$ cells $\left({ }^{*} \mathrm{P}<0.05 ;{ }^{*} \mathrm{P}>0.05\right.$ compared with the non-treated group; $\left.\mathrm{n}=3\right)$. (D) The percentage of cells in the G0/G1 phase in WT NSCs treated with the $\mathrm{IC}_{50}$ concentration of isoflurane was greater compared with that in the untreated group. This did not apply for the p53 $3^{-/} \mathrm{NE}-4 \mathrm{C}$ cells $\left({ }^{* *} \mathrm{P}<0.01 ;{ }^{*} \mathrm{P}<0.05 ;{ }^{*} \mathrm{P}>0.05\right.$ compared with the non-treated group; $\left.\mathrm{n}=3\right)$. NSCs, neural stem cells.

WT NSCs $(\mathrm{P}<0.01, \mathrm{n}=3)$ in a dose-dependent manner (Fig. 1). Furthermore, following treatment of the WT NSCs with the concentration of isoflurane which caused $50 \%$ inhibition $\left(\mathrm{IC}_{50}=0.246 \mathrm{mM}\right)$, cell proliferation was significantly inhibited at all time points studied $(\mathrm{P}<0.01, \mathrm{n}=3)$. By contrast, no difference was observed in the proliferation rate of NE-4C $\left(\mathrm{p} 53^{-/}\right)$ cells in the presence of isoflurane compared with the controls at any time point $(\mathrm{P}>0.05, \mathrm{n}=3$; Fig. 1$)$. The complete inhibition of proliferation induced by isoflurane in WT NSCs appears to occur during the G0/G1 phase, as determined from the FACS profile (Fig. 1).

Isoflurane activates p53-dependent Lkb1-p21 signalling in $N S C s$. RT-qPCR revealed that the mRNA expression levels of $L k b 1, p 53$ and $p 21$ were increased in WT NSCs treated with the $\mathrm{IC}_{50}$ concentration of isoflurane $(\mathrm{P}>0.05, \mathrm{n}=3$ compared with the control) (Fig. 2). However, the expression levels of the NSC marker, Nestin, and a cell proliferation marker, survivin, were significantly lower under these conditions ( $\mathrm{P}>0.05, \mathrm{n}=3$ ) (Fig. 2). The situation was more variable in NE-4C (p53-/) cells. The expression levels of Lkbl, nestin and survivin were significantly different following isoflurane treatment $(\mathrm{P}<0.01, \mathrm{n}=3)$, whereas the expression levels of p53 and p21 remained unchanged (Fig. 2). Western blotting revealed that the expression levels of Lkb1 and p21 in isoflurane-treated WT NSCs were significantly increased compared with the control $(\mathrm{P}<0.01, \mathrm{n}=3)$. By contrast, only $\mathrm{Lkb} 1$ was induced at the protein level in isoflurane-treated NE-4C cells $(P<0.01, n=3)$. GAPDH was used as a loading control. The immunofluorescence analysis yielded results which were consistent with those of western blotting (Figs. 3 and 4).

Isoflurane induces p53 Ser15 phosphorylation and increased levels of promoter binding in WT NSCs. An increase in p53 Ser15 phosphorylation was observed following treatment of the WT NSCs with the $\mathrm{IC}_{50}$ concentration of isoflurane $(\mathrm{P}<0.01, \mathrm{n}=3$ compared with the control) (Fig. 5A). However, in the NE-4C $\left(\mathrm{p} 53^{-/}\right)$cells, the protein signal of p53 and Ser15-phosphorylated p53 in the isoflurane-treated group was not significantly different compared with that in the untreated cells ( $\mathrm{P}>0.05, \mathrm{n}=3$ ) (Fig. 5A). Subsequently, a ChIP assay was used to determine whether isoflurane increased the quantity of $\mathrm{p} 53$ protein binding a target promoter. The binding efficiency of p53 to two independent p53 protein-binding sites located in the $p 21$ promoter was much higher following treatment $(\mathrm{P}<0.01, \mathrm{n}=3$ compared with the control) (Fig. 5B). However, no significant differences were identified in the isoflurane-treated NE-4C ( $\left.553^{-/}\right)$group or the untreated group $(\mathrm{P}>0.05, \mathrm{n}=3$ ) (Fig. 5B). These results indicated that the gene promoter activity of p21 is increased in WT NSCs in the presence of isoflurane.

\section{Discussion}

Following mammalian nerve cell injury, there is a spontaneous induction of NSC migration to sites of nerve injury, followed by appropriate repair of the damaged tissue to restore the original neuronal function (14). Therefore, NSCs have an important role in the repair of nerve injury and in nerve 
A
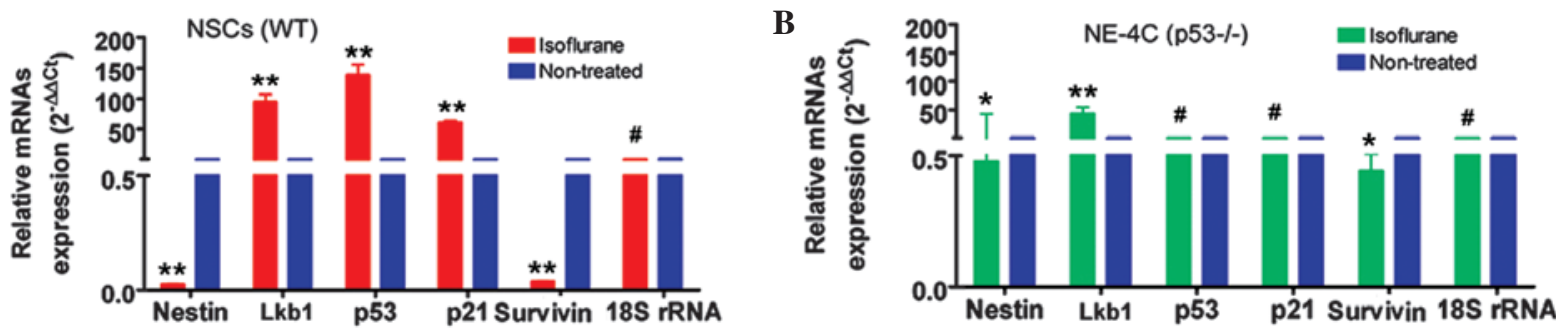

$\mathbf{C}$
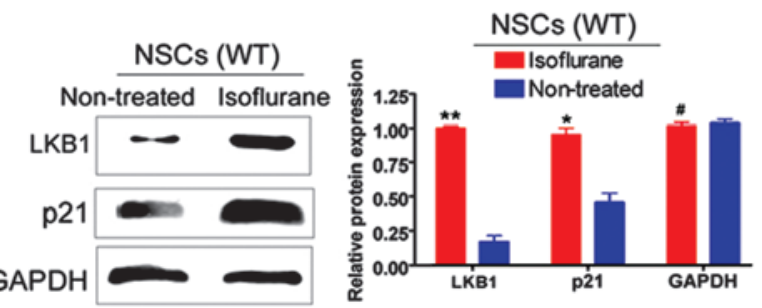

D

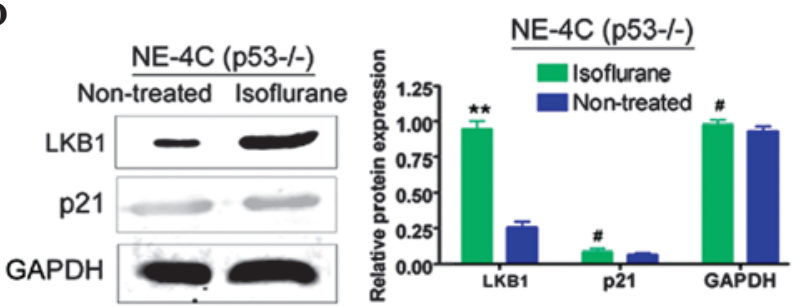

Fig. 2. Isoflurane activates Lkb1-p21 signalling in WT NSCs, although not in NE-4C (p53 ${ }^{-1}$ ) cells. (A) RT-qPCR analysis reveals that the mRNA expression levels of $L k b 1, p 53$ and $p 21$ in WT NSCs treated with an $\mathrm{IC}_{50}$ concentration of isoflurane were significantly higher compared with that in untreated cells $\left({ }^{* *} \mathrm{P}<0.01 ;{ }^{*} \mathrm{P}>0.05\right.$ compared with the non-treated group; $\left.\mathrm{n}=3\right)$. (B) RT-qPCR analysis indicates that the mRNA expression levels of $\mathrm{p} 53$ and $\mathrm{p} 21$ in isoflurane-treated NE-4C $\left(\mathrm{p} 53^{-/}\right)$cells were unchanged compared with the untreated cells $\left({ }^{* *} \mathrm{P}<0.01 ;{ }^{*} \mathrm{P}<0.05\right.$; ${ }^{*} \mathrm{P}>0.05$ compared with the non-treated group; $n=3$ ). (C) Western blotting indicates that the protein expression levels of Lkb1 and p21 in isoflurane-treated WT NSCs were significantly increased compared with untreated cells ( ${ }^{* *} \mathrm{P}<0.01$; ${ }^{*} \mathrm{P}<0.05$; $\mathrm{P}>0.05$ compared with the non-treated group; $\mathrm{n}=3$ ). (D) Western blotting indicates that only the protein expression level of Lkb1 was increased in isoflurane-treated NE-4C $\left(\mathrm{p} 53^{-/}\right)$cells ${ }^{* * *} \mathrm{P}<0.01 ;{ }^{*} \mathrm{P}>0.05$ compared with the non-treated group; $\left.\mathrm{n}=3\right)$. GAPDH was used as a loading control. RT-qPCR, reverse transcription-quantitative polymerase chain reaction; GAPDH, glyceraldehyde-3-phosphate dehydrogenase; WT NSCs, wild-type neural stem cells.

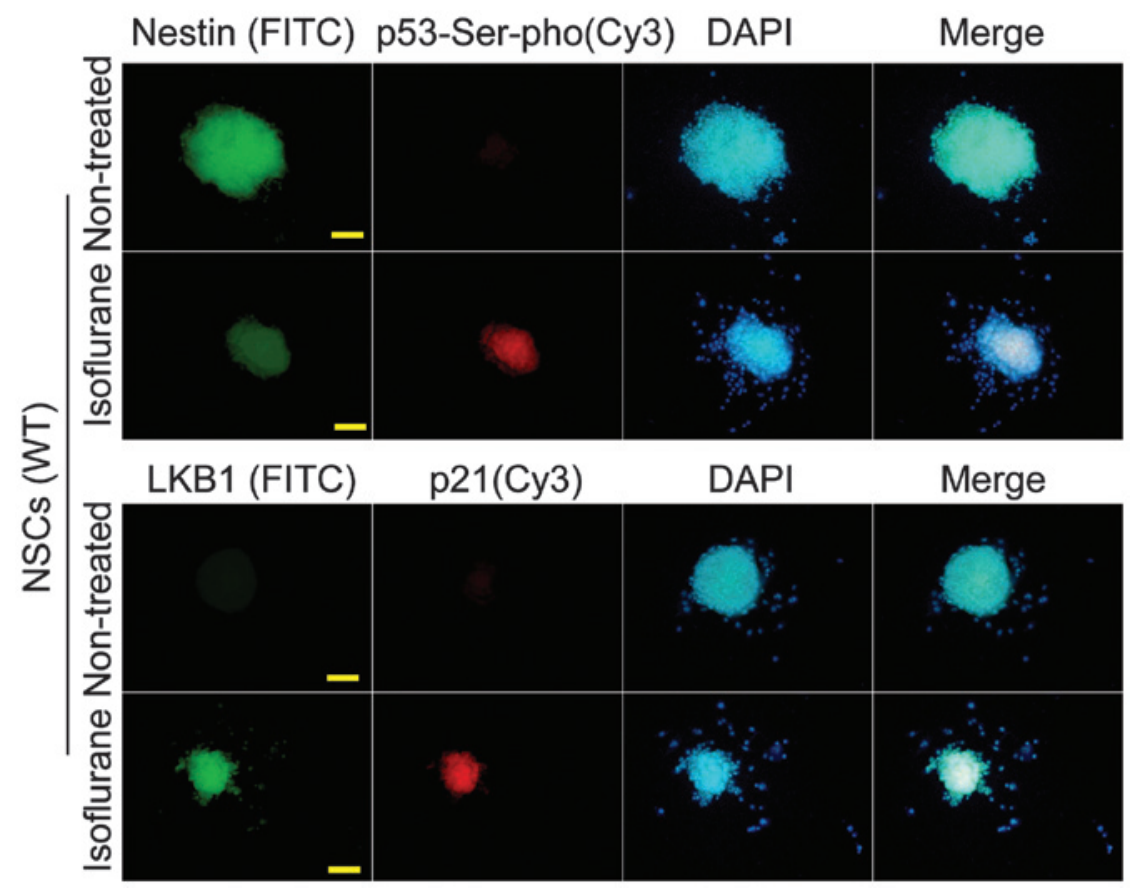

Fig. 3. Immunofluorescence analysis of the Lkb1-p21 signalling pathway in WT NSCs. The protein expression levels of LKB1, p53-Ser-pho and p21 in isoflurane-treated WT NSCs were significantly increased compared with the untreated cells (scale bar, $50 \mu \mathrm{m}$ ). FITC, fluorescein isothiocyanate; DAPI, 4',6-diamidino-2-phenylindole; WT NSCs, wild-type neural stem cells; p53-Ser-pho, Ser15-phosphorylated p53.

regeneration (14). As a well-established inhalational anesthetic, isoflurane is generally considered to induce ischemic tolerance in the myocardium, cerebrum and spinal cord (1-6), however, the effects of isoflurane on NSCs have not been extensively studied. In the present study, a dose-dependent inhibition of mouse neural cell proliferation was observed.
These results suggested that this may contribute to certain of the side effects of isoflurane. The additional experiments gave further credence to the hypothesis that the Lkb1-p53-p21 signalling pathway exerts a role in this response. A number of reports have indicated that this pathway is important in the regulation of cell proliferation (7-13). In response to specific 


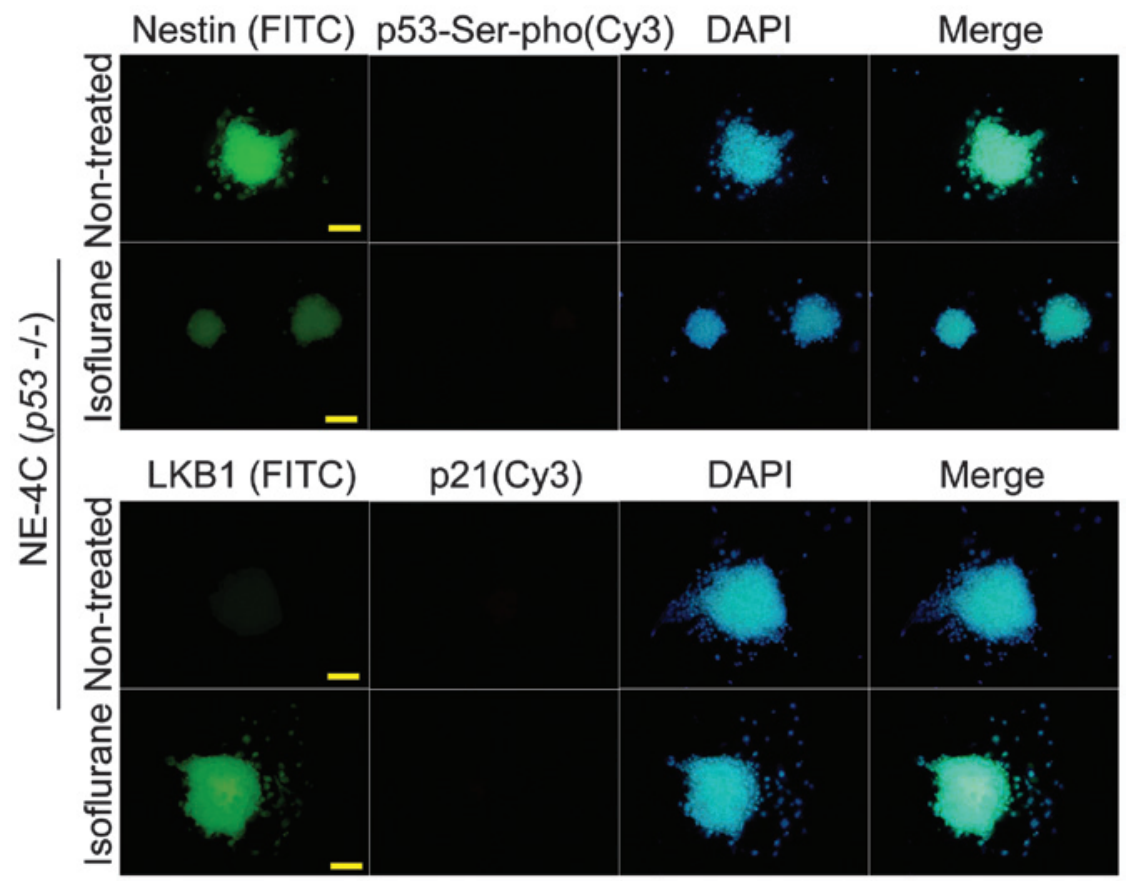

Fig. 4. Immunofluorescence analysis of the Lkb1-p21 signalling pathway in NE-4C (p53-1) cells. Only Lkb1 expression was increased in isoflurane-treated NE-4C (p53 $3^{-/}$) cells compared with the untreated controls (scale bar, $50 \mu \mathrm{m}$ ). FITC, fluorescein isothiocyanate; DAPI, 4',6-diamidino-2-phenylindole; WT NSCs, wild-type neural stem cells; p53-Ser-pho, Ser15-phosphorylated p53.
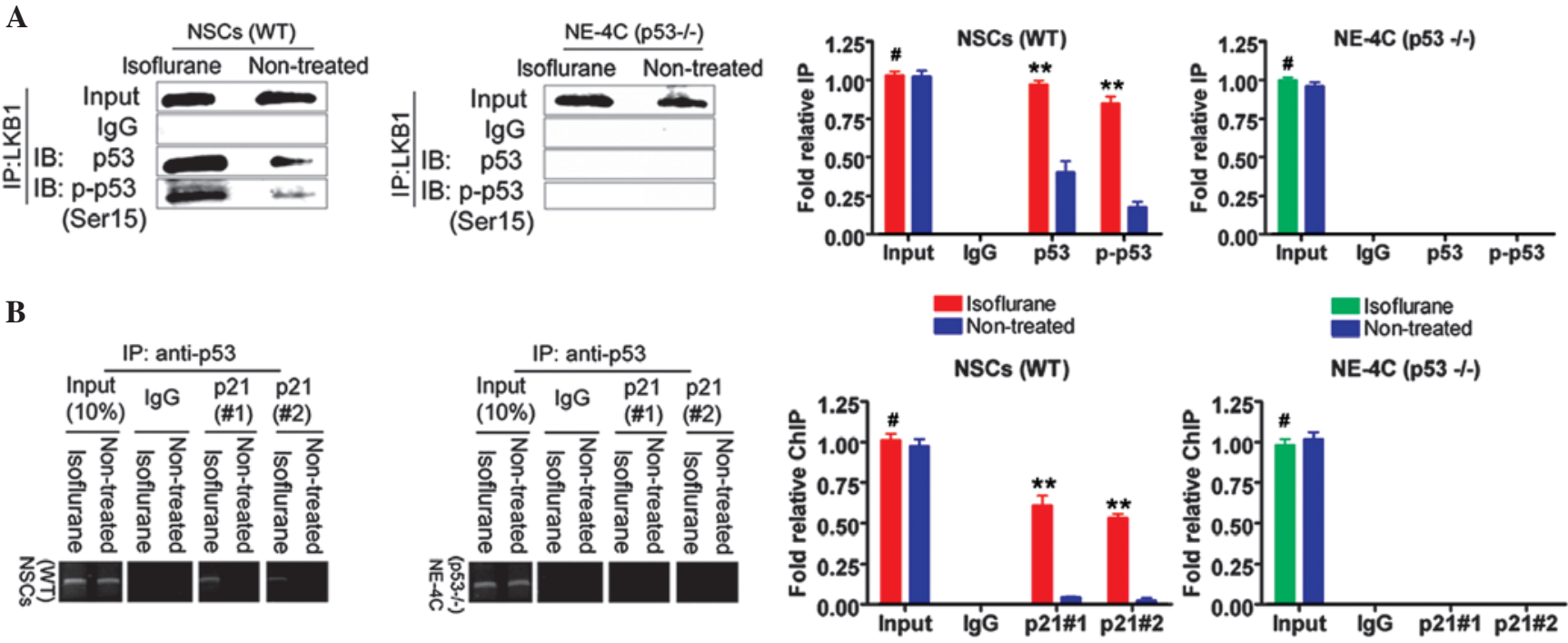

Fig. 5. Isoflurane induces $\mathrm{p} 53$ Ser15 phosphorylation and increases p53-dependent $\mathrm{p} 21$ transcriptional activity in WT NSCs, although not in NE-4C (p53 $3^{-/}$) cells (A) Following the enrichment of the total p53 protein by immunoprecipitation, western blotting revealed a significant increase in the proportion of phospho-Ser15-p53 in the isoflurane-treated cells $\left({ }^{* *} \mathrm{P}<0.01\right.$; ${ }^{*} \mathrm{P}>0.05$ compared with the non-treated group; $\left.\mathrm{n}=3\right)$. (B) ChIP-polymerase chain reaction revealed that the binding efficiency of $\mathrm{p} 53$ to the $p 21$ promoter at two independent p53 protein-binding sites was much higher following isoflurane treatment $\left({ }^{* *} \mathrm{P}<0.01 ;{ }^{*} \mathrm{P}>0.05\right.$ compared with the non-treated group; $\left.\mathrm{n}=3\right)$. ChIP, chromatin immunoprecipitation assay; IB, immunoblot; IgG, immunoglobulin G; $\mathrm{p}-\mathrm{p} 53$, Ser15-phosphorylated p53; WT NSCs, wild-type neural stem cells.

stimuli, LKB1 phosphorylates the p53 transcription factor at specific sites $(9,12)$, which increases the affinity of p53 for its target promoters, including that of the $p 21$ gene, thereby increasing target gene expression $(9,12)$. The expression of p21 elicits cell cycle arrest, which, in certain contexts, may be followed by apoptosis $(9,12)$. The present study revealed that the expression of Lkb1, p53 and p21 increased in WT NSCs, although not in the $\mathrm{NE}-4 \mathrm{C}\left(\mathrm{p} 53^{-/}\right)$cells, following isoflurane treatment. Furthermore, isoflurane promoted p53 Ser15 phosphorylation and increased the binding of p53 to the $p 21$ promoter.

Taken together, the results suggest that the Lkb1-p53-p21 signalling pathway is important in the response of NSCs to isoflurane. Further studies are required to determine whether 
this is of clinical relevance, and whether the manipulation of p53 activation may help to attenuate the side effects of isoflurane.

\section{Acknowledgements}

This study was supported by grants from the National Natural Science Foundation of China (no. 81202811) and a project funded by the China Postdoctoral Science Foundation (nos. 2014M550250 and 2015T80455) and the Shanghai Municipal Health Bureau Fund (no. 20124320).

\section{References}

1. Sang H, Cao L, Qiu P, Xiong L, Wang R and Yan G: Isoflurane produces delayed preconditioning against spinal cord ischemic injury via release of free radicals in rabbits. Anesthesiology 105: 953-960, 2006

2. Zheng S and Zuo Z: Isoflurane preconditioning reduces purkinje cell death in an in vitro model of rat cerebellar ischemia. Neuroscience 118: 99-106, 2003

3. Xiong L, Zheng Y, Wu M, Hou L, Zhu Z, Zhang X and Lu Z: Preconditioning with isoflurane produces dose-dependent neuroprotection via activation of adenosine triphosphate-regulated potassium channels after focal cerebral ischemia in rats. Anesth Analg 6: 233-237, table of contents, 2003.

4. Zheng S and Zuo Z: Isoflurane preconditioning induces neuroprotection against ischemia via activation of P38 mitogen-activated protein kinases. Mol Pharmacol 65: 1172-1180, 2004.

5. Kapinya KJ, Löwl D, Fütterer C, Maurer M, Waschke KF, Isaev NK and Dirnagl U: Tolerance against ischemic neuronal injury can be induced by volatile anesthetics and is inducible NO synthase dependent. Stroke 33: 1889-1898, 2002.
6. Park HP, Jeon YT, Hwang JW, Kang H, Lim SW, Kim CS and Oh YS: Isoflurane preconditioning protects motor neurons from spinal cord ischemia: Its dose-response effects and activation of mitochondrial adenosine triphosphate-dependent potassium channel. Neurosci Lett 387: 90-94, 2005.

7. Ollila S and Mäkelä TP: The tumor suppressor kinase LKB1: Lessons from mouse models. J Mol Cell Biol 3: 330-340, 2011.

8. Liu W, Monahan KB, Pfefferle AD, Shimamura T, Sorrentino J, Chan KT, Roadcap DW, Ollila DW, Thomas NE, Castrillon DH, et al: LKB1/STK11 inactivation leads to expansion of a prometastatic tumor subpopulation in melanoma. Cancer Cell 21: 751-764, 2012.

9. Liu T, Qin W, Hou L and Huang Y: MicroRNA-17 promotes normal ovarian cancer cells to cancer stem cells development via suppression of the LKB1-p53-p21/WAF1 pathway. Tumour Biol 36: 1881-1893, 2015.

10. Krock B, Skuli N and Simon MC: The tumor suppressor LKB1 emerges as a critical factor in hematopoietic stem cell biology. Cell Metab 13: 8-10, 2011.

11. Veeranki S, Hwang SH, Sun T, Kim B and Kim L: LKB1 regulates development and the stress response in Dictyostelium. Dev Biol 360: 351-357, 2011.

12. Zeng PY and Berger SL: LKB1 is recruited to the p21/WAF1 promoter by $\mathrm{p} 53$ to mediate transcriptional activation. Cancer Res 66: 10701-10708, 2006

13. Liang $X$, Wang $P$, Gao Q, Xiang T and Tao X: Endogenous LKB1 knockdown accelerates $\mathrm{G}(1) / \mathrm{S}$ transition through $\mathrm{p} 53$ and $\mathrm{p} 16$ pathways. Cancer Biol Ther 9: 156-160, 2010.

14. Ren W, Guo Q, Yang Y and Chen F: bFGF and heparin but not laminin are necessary factors in the mediums that affect NSCs differentiation into cholinergic neurons. Neurol Res 28: 87-90, 2006. 